\title{
Gender difference in the effects of interleukin- 6 on grip strength - a systematic review and meta-analysis
}

\author{
Alexandra Mikó ${ }^{1}$, László Pótó ${ }^{1,2}$, Péter Mátrai ${ }^{1,2}$, Péter Hegyi ${ }^{1,3,4}$, Nóra Füredi ${ }^{5}$, András Garami ${ }^{1}$, Anita Illés ${ }^{6}$, \\ Margit Solymár ${ }^{1}$, Áron Vincze ${ }^{6}$, Márta Balaskó ${ }^{1}$, Gabriella Pár ${ }^{6}$, Patrícia Sarlós ${ }^{6}$, Judit Bajor ${ }^{6}$, Judit Tenk \\ \|dikó Rostás ${ }^{1}$ and Erika Pétervári ${ }^{*}$
}

\begin{abstract}
Background: Aging sarcopenia characterized by low muscle mass with low muscle strength affects men and women differently. The contribution of interleukin-6 (IL-6) to sarcopenia has been suggested based on a negative correlation between plasma IL-6 and muscle function described by some studies. However, no consensus regarding clinically relevant cut-off criteria has been reached. Another question arises whether pooling male and female data is an accurate way to determine the predictive value of IL-6 in sarcopenia. The present meta-analysis was designed to assess: (1) whether plasma IL-6 in aged populations in fact correlates negatively to muscle strength; (2) whether such a correlation exists both in men and in women; and (3) whether plasma IL-6 shows a gender difference in old age.
\end{abstract}

Methods: We applied the preferred reporting items for systematic review and meta-analysis protocols (PRISMA). We searched PubMed and Embase for papers that reported data on individuals over 65 without inflammatory diseases. We extracted either separate male and female data on plasma IL-6 along with at least one muscle parameter or correlation coefficient between plasma IL-6 and these parameters. Random effect models calculated with DerSimonian and Laird weighting methods were applied to analyze correlation coefficients and gender difference in plasma IL-6. Egger's test was used to assess the small study effect.

Results: Twenty articles out of 468 records identified were suitable for analyses. Plasma IL-6 correlates negatively with grip strength in mixed populations and also separately in men [ 0.25 with 95\% confidence interval (Cl): $-0.48,-0.02]$ and in women $(-0.14$ with $95 \% \mathrm{Cl}:-0.24,-0.03)$. However, contrary to expectations, men with better muscle condition have higher plasma IL-6 than women of similar age with worse muscle condition (plasma IL-6 male-female difference: $0.25 \mathrm{pg} / \mathrm{mL}$ with $95 \% \mathrm{Cl}: 0.15,0.35)$.

Conclusion: This is the first study to demonstrate that a higher predictive IL-6 cut-off level should be determined for aging sarcopenia in men than in women.

Keywords: Sarcopenia, Inflammation, Interleukin-6, Grip strength, Gender

\footnotetext{
* Correspondence: erika.petervari@aok.pte.hu

${ }^{1}$ Institute for Translational Medicine, Medical School, University of Pécs,

Szigeti út 12, Pécs 7624, Hungary

Full list of author information is available at the end of the article
}

(C) The Author(s). 2018 Open Access This article is distributed under the terms of the Creative Commons Attribution 4.0 International License (http://creativecommons.org/licenses/by/4.0/), which permits unrestricted use, distribution, and reproduction in any medium, provided you give appropriate credit to the original author(s) and the source, provide a link to the Creative Commons license, and indicate if changes were made. The Creative Commons Public Domain Dedication waiver (http://creativecommons.org/publicdomain/zero/1.0/) applies to the data made available in this article, unless otherwise stated. 


\section{Background}

Population aging particularly affects women (since they live longer) resulting in the "feminization of old age" [1]. Women are especially affected by "aging sarcopenia", defined by the European Working Group on Sarcopenia in Older People as a geriatric syndrome characterized by progressive, generalized loss of muscle mass and muscle strength or physical performance without necessary occurrence of any disease [2]. Sarcopenia is of outstanding clinical importance, as it leads to frailty, tiredness, falls, fractures, functional disabilities, comorbidities, higher health care expenditure and premature mortality [3].

Immunosenescence that involves chronic systemic, low-grade inflammation coined as "inflammaging" contributes to the progression of aging sarcopenia [4]. Inflammatory cytokines, e.g. interleukin-6 (IL-6), have catabolic effects on muscle proteins [5]. This mediator is called the cytokine of gerontologists [6]. The main sources of this Janus-faced cytokine with pro- and antiinflammatory features include immune or endothelial cells and adipocytes [7]. Plasma IL-6 (pIL-6) increases with age both in healthy men and women [8,9], but gender differences still remain largely unexplored. Body composition, especially visceral fat, also correlates to IL-6. As a myokine, pIL-6 increases for several hours following exercise [10], but chronically active persons have lower pIL-6 [11].

There are controversies regarding IL-6 in the literature. On the one hand, pIL- 6 released during muscle contraction inhibits pro-inflammatory cytokines [12]; on the other hand, it is a marker of inflammatory status [4] and a predictor of disability and mortality in the elderly [13]. Sarcopenia could be the link between high pIL-6 and disability. Plasma IL-6 has been shown to be negatively correlated to muscle mass and function (mostly indicated by grip strength) in the elderly [14-28]. Follow-up studies $[29,30]$ have also suggested a role for pIL-6 as a biomarker of sarcopenia. In contrast, other studies have failed to confirm a similar relationship [9, 20, 24, 25, 31]. Gender differences may be the confounder that explains the controversy. Pooling male and female data may not be an accurate way to determine the predictive value of pIL-6 in sarcopenia. However, gender differences have not been properly analyzed, although this is a clinically relevant question.

A recent meta-analysis has suggested an association of elevated pIL- 6 with frailty that has not been confirmed by longitudinal studies [32]. However, one of three longitudinal studies applied too high a detection limit of pIL-6, at which level the association may not be seen. Another recent meta-analysis failed to detect any association between pIL-6 and sarcopenia [33]. This latter review may have underestimated the influence of chronic diseases on PIL-6, since some of its studies reported extremely high pIL-6 in all participants, thus abolishing the standardized mean differences (SMD) between the sarcopenic and control groups [33]. Moreover, gender may also influence this association, since women with lower muscle strength have also shown lower (instead of higher) pIL-6 compared to men [8, 9, 34]. To date, no systematic review has analyzed this association separately in men and women. We therefore aimed to review the literature complemented by a meta-analysis to investigate the correlation between pIL- 6 and muscle mass or strength in men and women.

\section{Methods}

\section{Search strategy}

The PRISMA principles [35] and MOOSE guidelines were followed. No review protocol was registered for this meta-analysis. The PubMed and Embase databases were systematically searched in August 2017 (see search strategy in Additional file 1). The following search terms were used: "interleukin-6" AND "muscle strength"; "interleukin-6" AND "muscle mass". Articles were limited to human studies with participants over 65 years (mean or median value). Two hundred seventy-five records for "muscle strength" and 193 for "muscle mass" were identified altogether.

\section{Study selection}

Selection was conducted separately by two investigators (AM and NF). Disagreements were resolved by a third reviewer (EP). Animal experiments, non-Englishlanguage reports and studies with all participants suffering from inflammatory diseases/states characterized by extremely high pIL-6 (e.g. renal failure, cancer, osteoarthritis, rheumatoid arthritis, chronic obstructive pulmonary diseases, sepsis, surgical interventions or cirrhosis) were excluded. Only groups without any intervention were included in two settings. Eligibility criteria for the first setting: presence of correlation coefficient regarding pIL-6 and any of the muscle parameters (muscle strength estimated by handgrip or knee extension or $4 \mathrm{~m}$ gait speed or chair stand or timed up and go or 6-min walk tests; muscle mass; fat-free mass; lean mass). Second setting: pIL-6 with at least one muscle parameter reported separately for male and female groups in the same study.

\section{Assessment of study quality}

Strengthening the Reporting of Observational Studies in Epidemiology criteria (STROBE) [36] were used to assess the quality of the studies included. As few appropriate reports were available, we could not exclude studies based on lack of randomization, blinding or low participant number. Due to weighting methods, data with low participant numbers were assigned lower weights. 


\section{Data extraction}

Only data published in the original articles were extracted; no supplementary information was obtained. Data on patients with inflammatory diseases were excluded, but those of their controls were used. The following data were extracted: sample size, gender, age, mean ( \pm standard deviation or standard error) or median (with quartiles) values of pIL-6 (converted to $\mathrm{pg} / \mathrm{mL}$ ) along with muscle parameters and correlation coefficients (if present).

\section{Data synthesis and analysis}

A random effect model using the DerSimonian and Laird weighting was applied to account for study heterogeneity. To assess heterogeneity, the $\mathrm{Q}$ test and $\mathrm{I}^{2}$ indicator were calculated. A significant $\mathrm{Q}$ test $(p<0.1)$ or $\mathrm{I}^{2}$ higher than $50 \%$ indicated high heterogeneity. The estimated effect size (ES) was reported by the weighted mean with $95 \%$ confidence intervals $(95 \% \mathrm{CI})$ and $p<0.05$ was regarded as significant. To assess small study effect, we used Egger's test to detect asymmetry in the funnel plot. A significant result $(p<0.1)$ indicates the existence of bias across studies.

With regard to correlations between pIL-6 and muscle parameters, the coefficients do not show normal distribution; therefore, Fisher's $\mathrm{z}$ transformation was performed
[37] with subgroup analyses of the male and female populations. Then, the results were back-transformed to correlation coefficients for interpretation purposes.

With regard to gender differences, we also analyzed male minus female differences of mean pIL- 6 from studies that contained both male and female groups (effect size: paired difference). Gender differences in their age and muscle parameters were also tested. Due to differences in the methods and measurement scales for the assessment of muscle strength or mass, we had to use SMDs. For data on certain up and go and chair stand tests that were supplied in seconds (i.e. smaller values indicate better muscle performance), we reversed the sign of the difference. Medians with quartiles (not suitable for meta-analysis) were transformed to means with standard deviations [38].

Comprehensive Meta-Analysis Software V3.3 (Biostat Inc.) and Stata 11 SE (Stata Corp.) were employed.

\section{Results}

Study selection

Two hundred fifty of the 468 items identified remained after duplicates were removed (Fig. 1). An initial screening of titles and abstracts removed non-English-language

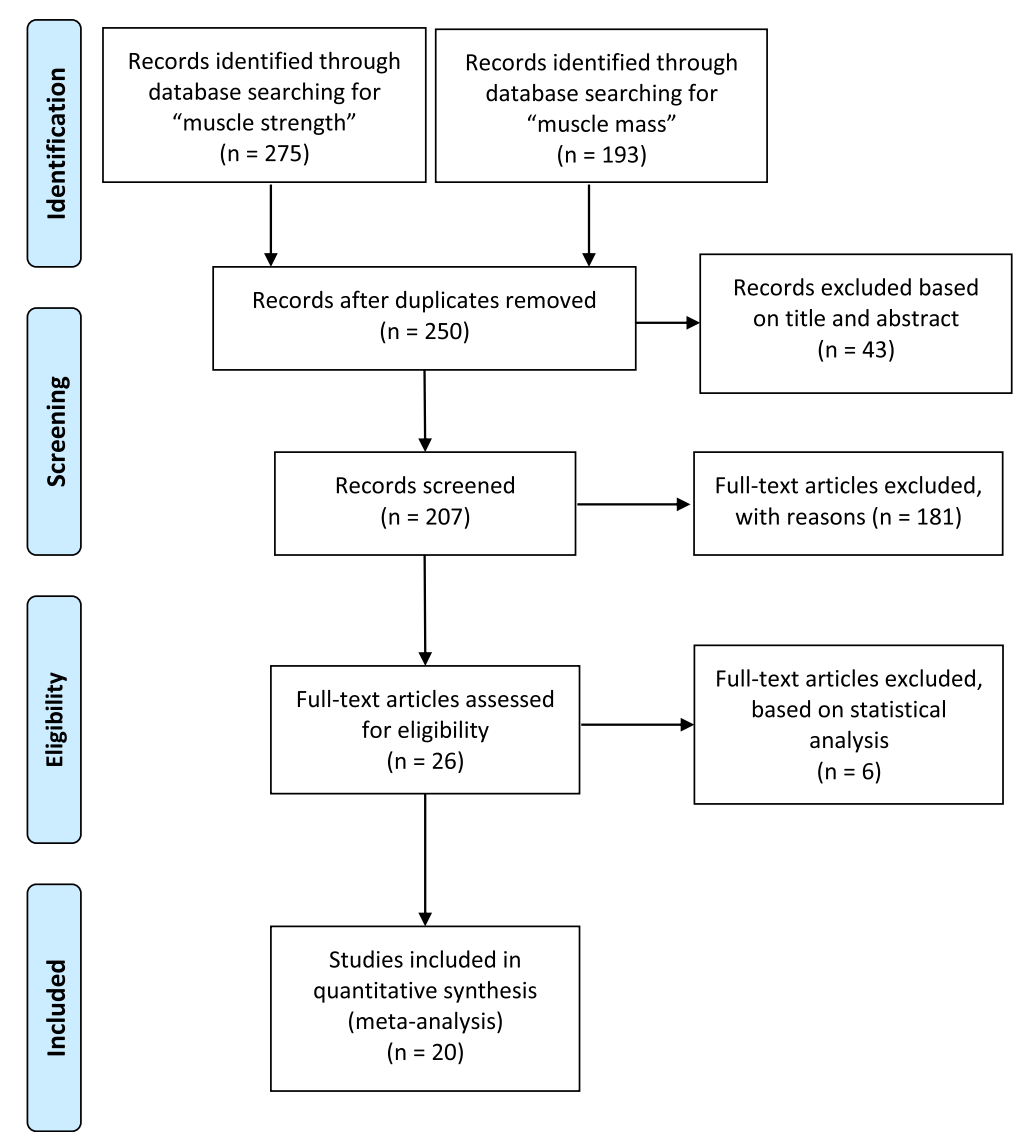

Fig. 1 Flowchart of the study selection procedure 
articles, animal studies, and those without full-text availability. A further 181 of the 207 full-text articles were excluded due to missing participant data, inappropriate age or comorbidities. The eligible 26 articles contained either (1) separate male and female data on pIL-6 along with corresponding muscle strength/mass values or (2) a correlation coefficient of association between PIL-6 and muscle parameters. Only the correlation coefficients for pIL-6 and handgrip strength (GS), the most widely used parameter, were analyzed, since numbers of studies reporting other muscle parameters were not statistically sufficient (knee extension test: $5 ; 4 \mathrm{~m}$ walk gait speed test: 2; 6-min walk test: 1; chair stand test: 3 ; muscle mass: 3$)$. One study was excluded based on different mean ages for the male vs. female groups, and five studies were ruled out due to out-of-range correlation coefficients. The remaining 20 articles were included in the meta-analysis [14-18, 20, 23-25, 27-29, 31, 39-45] shown in the Table in Additional file 2.

\section{Study characteristics}

Studies analyzed dated from 1995 to 2016. Sample size, gender, age and correlation coefficient and/or pIL-6 along with muscle strength/mass values for the same groups, provided separately for male and female populations, were extracted. Based on STROBE quality indicators (Additional file 3), we included all the data without exclusion.

Eleven $[15-18,20,23-25,27,28,31]$ of the 20 studies (involving a total of 3244 individuals ranging from 21 to 1020 /study) investigated the correlation between pIL-6 and GS with 13 coefficients, since two analyzed correlations separately for male and female populations [24, 25]. Five studies $[15-17,20,28]$ contained mixed data for male and female volunteers, while two studies each involved exclusively either men $[18,27]$ or women $[23,31]$.

Some authors reported a Pearson linear correlation $[15,18,20,23,25,28]$ sensitive only to linear associations, but others calculated the Spearman rank correlation [16, 24, 31], which measures any monotonous association. Both yield results between -1 and 1 . We used both types because this feature only affects the strength of the association, not its direction. Therefore, we only drew conclusions on the direction of the association. Correlations using a logarithmic [23, 25] or square root transformation [20] of pIL-6 were included, since these strictly monotonous transformations do not affect the direction of the association. Nine subgroups [15-18, $20,23,24,27,28]$ showed significant negative correlation, and only four failed to reveal any significant association $[24,25,31]$.

Twelve of the 20 studies (involving 7209 individuals ranging from 10 to 1154/study, 3298 men and 3911 women) contained separate male and female data on pIL-6 with corresponding muscle parameters $[14,15,24$,
25, 29, 39-45]. One study [43] carried out the measurements in three different subgroups (with data for men and women, separately) providing independent data items. Male minus female differences in muscle parameters (GS, up and go test, chair stand test, knee extension test, 6-min walk test, fat-free mass, lean mass, thigh muscle area and muscle volume) and in age were also analyzed. With regard to muscle parameters, 26 pieces of data (male minus female SMD) were available, since individual studies provided up to three muscle parameters characterizing their male-female groups. Two studies $[24,44]$ that reported only the age range of the participants could not be used for an age comparison.

\section{Analysis of data and publication bias}

An analysis of the correlation coefficients using Fisher's $\mathrm{z}$ transformation demonstrated a significant negative correlation between pIL- 6 and GS in the 13 groups within the 11 studies (Fig. 2). To facilitate interpretation, weighted overall estimates (ES) were back-transformed to correlation coefficients: $\mathrm{ES}=-0.15$ with $95 \%$ confidence interval (CI) $(-0.20,-0.10) ; p<0.001$. Little heterogeneity of data was found: $p=0.15, \mathrm{I}^{2}=29.4 \%$. A small study effect was identified using Egger's test: $p=0.044$ for the correlation coefficient indicating some missing small studies with low correlation (funnel plot in Additional file 4). We also analyzed correlation coefficients separately for male and female subgroups (Fig. 2). The analysis demonstrated similarly negative correlations in women $[23-25,31](E S=-0.14$ with $95 \%$ CI $(-0.24$, $-0.03) ; p=0.012)$ and men $[18,24,25,27](\mathrm{ES}=-0.25$ with $95 \%$ CI $(-0.48,-0.02) ; p=0.029)$. Subgroup analysis of male vs. female groups found no gender difference $(\mathrm{Q}=0.123, p=0.725)$.

Our results confirmed that pIL-6 negatively correlates with GS in both men and women. This confirmed negative correlation appears to suggest that men should have lower PIL-6 than women, because men have higher GS. However, it is not so. Some studies have reported that men with greater muscle strength also show higher pIL6 than women of the corresponding age group [8, 9, 34]. These unexpected findings suggest that the range of pIL-6 is not the same in men and women.

To test this hypothesis, we analyzed male minus female differences in mean pIL-6 in groups of similar age and different muscle conditions. In the 12 studies that contained male and female data, there was no significant difference in age (Additional file 5). At the same time, significantly better muscle condition was found in men (Additional file 6). A meta-analysis concerning male minus female differences in pIL- 6 in groups from the same studies showed a significantly higher pIL-6 (Fig. 3) in men with better muscle condition: $\mathrm{ES}=0.25$ with $95 \%$ CI $(0.15,0.35) ; p<0.001$. The heterogeneity of the data 


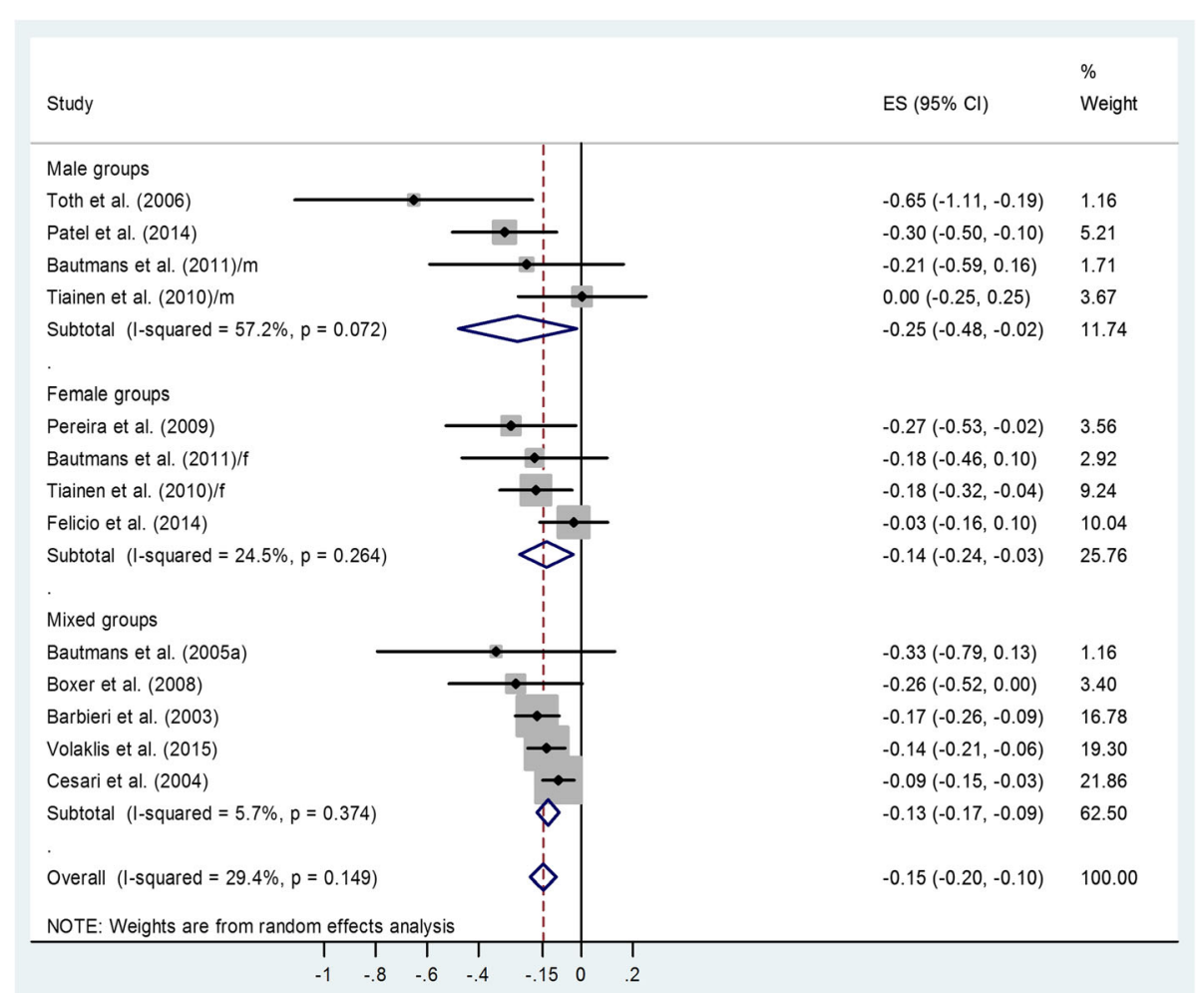

Fig. 2 Forest plot representing Fisher's z values concerning the relationship between plL-6 level and grip strength in male, female and mixed subgroups. Squares show the Fisher's $z$ values with the grey area reflecting the weight assigned to the study. Horizontal bars indicate $95 \%$ confidence intervals ( $95 \%$ CI). The diamond shows the overall effect size (ES) with its corresponding $95 \% \mathrm{Cl}$. In the case of two studies [24, 25], the coefficients for male and female groups were indicated by $m$ and $f$, respectively

was high: $p=0.022, \quad \mathrm{I}^{2}=48.4 \%$, indicating the contribution of other factors determining pIL-6. No small study effect was identified: $p=0.127$.

\section{Discussion}

We aimed to investigate the correlation between pIL-6 and muscle mass or strength in healthy elderly populations. Following the meta-analysis of the pooled data, correlation between pIL- 6 and GS could be tested and it was analyzed separately in males and females. We also compared the male vs. female pIL-6 values from the same studies.

\section{Correlation between plL- 6 and grip strength}

Our results showed a negative correlation between pIL-6 and GS in pooled and separate male and female elderly populations. The correlation coefficient was small but negative and similar in both genders. These results correspond with findings of the few available previous studies using other muscle parameters (muscle strength for knee flexion or extension [14, 18, 21, 26], 6-min walking distance [20], chair stand test [16], thigh [14] or leg muscle area [18]). Higher pIL-6 is associated not only with lower muscle mass/strength [14], but the higher level predicts a higher rate of muscle loss even in healthy elderly [46]. The most consistent relationship across different gender and race groups was observed for IL-6 and GS even after adjustment for age, health status, medications, physical activity, smoking, height and body fat [14]. Low physical performance is associated with low GS even after considering other risk factors for sarcopenia in the elderly, and low muscle strength has been reported to be a better indicator than low muscle mass [9]. GS is the most widely used indicator of sarcopenia in the elderly because this test is less influenced by agerelated degeneration of the joints, yet it shows a strong correlation with upper and lower body strength and physical performance [2].

In contrast, some reports have failed to confirm this relationship. In populations with a uniformly low level of IL-6 [24, 31], a negative corrrelation may not be statistically detectable. Nevertheless, in our meta-analysis, the negative correlation has been proven, despite the low mean pIL-6 (below 2-2.5 pg/mL) in healthy individuals.

Proinflammatory cytokine IL- 6 plays a central role in acute and chronic inflammatory diseases and geriatric syndromes (e.g. cardiovascular diseases, cancer, osteoporosis, chronic obstructive pulmonary disease, diabetes 


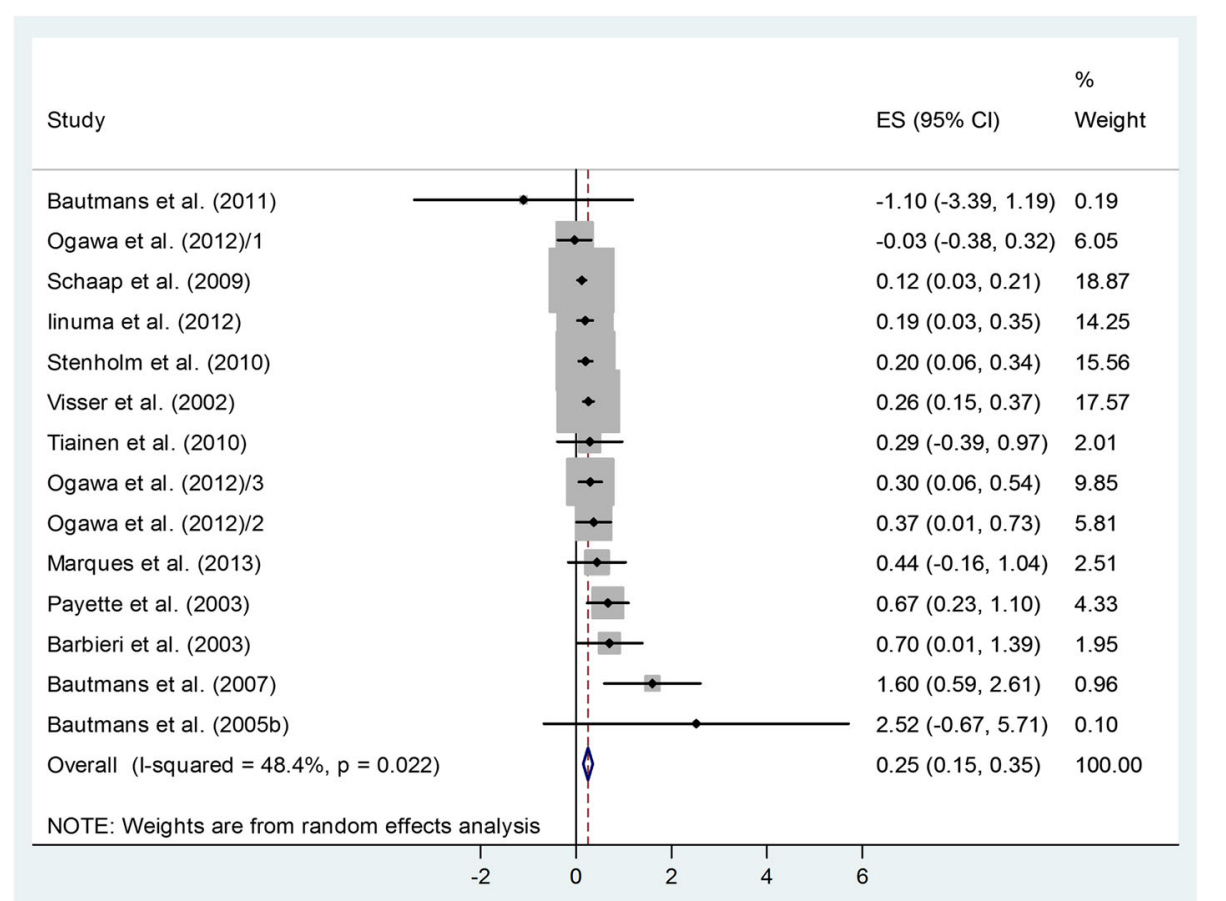

Fig. 3 Forest plot representing the male minus female differences in plL-6 from the same studies. Squares show the difference in mean values with the grey area reflecting the weight assigned to the study. Horizontal bars indicate 95\% confidence intervals (95\% Cl). The diamond shows the overall effect size (ES) with the corresponding 95\% Cl. Subgroups in Ogawa et al. [43] are indicated with Arabic numerals

mellitus, Alzheimer's disease and inflammatory bowel diseases) $[4,12,19]$. Other conditions, e.g. visceral obesity, smoking and stress, also trigger IL-6 release [47]. Nevertheless, several studies confirmed the negative correlation between pIL- 6 and muscle strength (GS or quadriceps strength) independently of disease status even in such pathological states (e.g. chronic heart failure, obstructive lung disease) $[18,19,22]$. Potential mechanisms have been suggested by experimental studies, but their results are not conclusive. In some studies administration of IL-6 was reported to increase skeletal muscle protein breakdown and to decrease the rate of protein synthesis and muscle amino acid concentrations leading to muscle wasting in rats [48, 49], whereas other research groups demonstrated a lack of such effects of IL-6 in mice [50,51]. In addition, a negative correlation has been found between IL-6 and endocrine regulators of muscle mass/strength, such as insulin-like growth factor-1 and dehydroepiandrosterone [52]. Based on these findings, a combination of high pIL-6, along with other inflammatory mediators and low levels of anabolic signals may contribute to the decline in muscle strength.

\section{Gender-related differences}

The inverse correlation discussed above would suggest that women with lower muscle strength have a higher pIL-6 level than men with better muscle condition. However, certain studies reported lower IL-6 in elderly females than in males of similar age $[8,9,34]$, while others failed to find any difference $[24,25]$. Our meta-analysis of male minus female differences revealed significantly higher pIL- 6 in men (despite better muscle condition) than in similarly elderly women (with weaker muscle condition). Different regulatory pathways of the female vs. male immune systems are suggested as an explanation. Moreover, gender difference may be observed in the age-related alterations of these regulatory pathways of the immune system [53]. Despite the similar negative correlations, males and females may be characterized by peculiar regression lines/curves. Therefore, blood samples collected from men should not be pooled with those of women. These findings may contribute to the explanation of the absence of a consensus cut-off point for the prediction of adverse physical and functional outcomes $[15,34]$. Thus, in future clinical studies, a higher cut-off value for IL- 6 must be defined for men than for women.

\section{Strengths and limitations}

The main strength of our analysis is that we are the first to analyze male and female populations separately. Moreover, we selected studies that recorded resting PIL-6, as pIL-6 level is transiently increased following exercise.

Limitations mainly stem from features of available studies. Studies that pooled samples of men and women also had to be included, whereas only a few reports were 
appropriate for a gender-based analysis of correlation. The small study effect with regard to correlation coefficients represents another limitation. In most studies, only mean age was supplied for a wide age range of participants, limiting the strength of an analysis of age. In addition, high heterogeneity with regard to gender difference in pIL-6 indicates the presence of other determining factors, e.g. diet, obesity, smoking, stress, undiagnosed inflammatory processes, different sample techniques and assay methods. Although our analysis focused on healthy elderly individuals, sporadic inflammatory conditions could not be completely excluded.

\section{Conclusions}

The plasma level for IL-6 correlates negatively and reportedly in a nonlinear fashion [34] with muscle strength; thus it is a potential biomarker of sarcopenia. The practical implication of our study is that a different interpretation of IL-6 as a biomarker of aging sarcopenia is needed in men and women in future studies. Accordingly, higher IL-6 cut-off values must be determined in men than in women with regard to aging sarcopenia.

\section{Additional files}

Additional file 1: Literature search strategy. (DOCX $14 \mathrm{~kb}$ )

Additional file 2: Description of the studies included in the meta-analysis $(n=20)$. (DOCX $22 \mathrm{~kb})$

Additional file 3: Quality assessment of the papers (observational studies) included based on guidelines from the STROBE statement. (DOCX $16 \mathrm{~kb}$ )

Additional file 4: Funnel plot of standard error using Fisher's z. The asymmetrical funnel plot represents the small study effect with regard to Fisher's z values derived from correlation coefficients. (TIF $40 \mathrm{~kb}$ )

Additional file 5: Forest plot representing the male minus female differences in mean age of corresponding groups from the same studies. Squares show the difference in mean values with the grey area reflecting the weight assigned to the study. Horizontal bars indicate $95 \%$ confidence intervals (95\% Cl). The diamond shows the overall effect size (ES) with the corresponding 95\% Cl. Subgroups in Ogawa et al. [43] are indicated with Arabic numerals. A lack of age difference was found: $\mathrm{ES}=0.14$ with $95 \% \mathrm{Cl}(-0.11,0.39) p=0.265$. The heterogeneity of the data was low: $p=0.195, I^{2}=25.3 \%$. No small study effect was identified using Egger's test: $p=0.487$. (TF $156 \mathrm{~kb}$ )

Additional file 6: Forest plot representing the male minus female standardized differences in mean values of various muscle parameters (muscle mass/strength/function) in corresponding groups from the same studies. Squares show the difference in mean values with the grey area reflecting the weight assigned to the study. Horizontal bars indicate $95 \%$ confidence intervals $(95 \% \mathrm{Cl})$. The diamond shows the overall effect size (ES) with the corresponding 95\% Cl. Subgroups in Ogawa et al. [43] are indicated with Arabic numerals. A: Grip strength; B: Chair stand test; C: 6-min walk; D: Lean mass; E: Up and go test; F: Muscle volume; G: Fat-free mass; $\mathrm{H}$ : Knee extension test; I: Thigh muscle area. Significantly higher muscle mass/strength/function was demonstrated in male than in female volunteers (i.e. positive standardized difference in mean values): $\mathrm{ES}=1.82$ with $95 \% \mathrm{Cl}(1.62,2.02) p<0.001$. The heterogeneity of the data was high: $p<0.001, I^{2}=95.4 \%$. No small study effect was identified using Egger's test: $p=0.163$. (TIF $295 \mathrm{~kb}$ )

\section{Abbreviations}

Cl: Confidence interval; ES: Effect size; GS: Grip strength; plL-6: plasma interleukin-6; PRISMA: Preferred reporting items for systematic review and meta-analysis; SMD: Standardized mean difference; STROBE: Strengthening the Reporting of Observational Studies in Epidemiology

\section{Acknowledgements}

The present paper is dedicated to the 650th anniversary of the founding of the University of Pécs, Hungary.

\section{Funding}

This study was supported by grants from the Hungarian Government (EFOP-3.6.2-16-2017-0006 to PH) and from the University of Pécs, Hungary (grant numbers: PTE ÁOK-KA No: 2017/12 to EP, PTE ÁOK-KA No: 2017/13 to MB, and PTE-AOK-KA-2015-14 to MS). The funders had no role in the design, execution, analysis and interpretation of the data or in writing the study.

Availability of data and materials

All data generated or analyzed during this review are reported in the manuscript (and additional files).

\section{Authors' contributions}

EP formulated the concept and the research question, designed the data extraction form, and drafted the manuscript. AM and NF screened the articles, extracted the data and participated in the drafting of the manuscript. LP and PM analyzed the data statistically, prepared figures and contributed to the drafting of the manuscript, especially to statistical aspects. IR and $\pi$ cross-checked the data extraction and critically revised the draft before submission. PH assisted in formulating the research question and supervised the quality of the paper. MS and MB aided in assessing the quality of the relevant articles and structured the review. Al, GP and PS contributed to the conception and design of the study and to the preparation of the manuscript. ÁV and JB supervised the interpretation of the data and the study design. AG supervised the statistical analyses and critically modified the data interpretation and revised the manuscript and contributed to the formulating of the conclusions. All the authors read, critically revised and approved the final manuscript and agreed to the publication of the final manuscript.

Ethics approval and consent to participate

Not applicable.

\section{Competing interests}

The authors declare they have no competing interests.

\section{Publisher's Note}

Springer Nature remains neutral with regard to jurisdictional claims in published maps and institutional affiliations.

\section{Author details}

${ }^{1}$ Institute for Translational Medicine, Medical School, University of Pécs, Szigeti út 12, Pécs 7624, Hungary. ${ }^{2}$ Institute of Bioanalysis, Medical School, University of Pécs, Szigeti út 12, Pécs 7624, Hungary. ${ }^{3}$ Department of Translational Medicine, First Department of Medicine, University of Pécs, Szigeti út 12, Pécs 7624, Hungary. ${ }^{4}$ Hungarian Academy of SciencesUniversity of Szeged, Momentum Gastroenterology Multidisciplinary Research Group, Korányi fasor 8-10, Szeged 6720, Hungary. ${ }^{5}$ Department of Anatomy, Medical School, University of Pécs, Szigeti út 12, Pécs 7624, Hungary. ${ }^{6}$ Division of Gastroenterology, First Department of Internal Medicine, University of Pécs, Ifjúság út 13, Pécs 7624, Hungary.

Received: 20 November 2017 Accepted: 30 April 2018

Published online: 08 May 2018

References

1. Perrig-Chiello P, Hutchison S. Health and well-being in old age: the pertinence of a gender mainstreaming approach in research. Gerontology. 2010;56(2):208-13.

2. Cruz-Jentoft AJ, Baeyens JP, Bauer JM, Boirie Y, Cederholm T, Landi F, Martin FC, Michel JP, Rolland Y, Schneider SM, Topinková E, Vandewoude M, Zamboni M. Sarcopenia: European consensus on definition and diagnosis: report of the European Working Group on Sarcopenia in Older People. Age Ageing. 2010;39(4):412-23.

3. Thomas DR. Sarcopenia. Clin Geriatr Med. 2010;26(2):331-46. 
4. Franceschi C, Campisi J. Chronic inflammation (inflammaging) and its potential contribution to age-associated diseases. J Gerontol A Biol Sci Med Sci. 2014;69(Suppl 1):S4-9.

5. Krabbe KS, Pedersen M, Bruunsgaard H. Inflammatory mediators in the elderly. Exp Gerontol. 2004;39(5):687-99.

6. Ershler WB. Interleukin-6: a cytokine for gerontologists. J Am Geriatr Soc 1993;41(2):176-81.

7. Pedersen BK, Steensberg A, Schjerling P. Muscle-derived interleukin-6: possible biological effects. J Physiol. 2001;536(Pt 2):329-37.

8. Ferrucci L, Corsi A, Lauretani F, Bandinelli S, Bartali B, Taub DD, Guralnik JM, Longo DL. The origins of age-related proinflammatory state. Blood. 2005; 105(6):2294-9.

9. Legrand D, Adriaensen W, Vaes B, Mathei C, Wallemacq P, Degryse J. The relationship between grip strength and muscle mass (MM), inflammatory biomarkers and physical performance in community-dwelling very old persons. Arch Gerontol Geriatr. 2013;57(3):345-51.

10. Nieman DC, Davis JM, Henson DA, Gross SJ, Dumke CL, Utter AC, Vinci DM, Carson JA, Brown A, McAnulty SR, McAnulty LS, Triplett NT. Muscle cytokine mRNA changes after $2.5 \mathrm{~h}$ of cycling: influence of carbohydrate. Med Sci Sports Exerc. 2005;37(8):1283-90.

11. Elosua R, Bartali B, Ordovas JM, Corsi AM, Lauretani F, Ferrucci L, InCHIANTI Investigators. Association between physical activity, physical performance, and inflammatory biomarkers in an elderly population: the InCHIANTI study. J Gerontol A Biol Sci Med Sci. 2005;60(6):760-7.

12. Maggio M, Guralnik JM, Longo DL, Ferrucci L. Interleukin-6 in aging and chronic disease: a magnificent pathway. J Gerontol A Biol Sci Med Sci. 2006; 61(6):575-84.

13. Ferrucci L, Harris TB, Guralnik JM, Tracy RP, Corti MC, Cohen HJ, Penninx B, Pahor M, Wallace R, Havlik RJ. Serum IL-6 level and the development of disability in older persons. J Am Geriatr Soc. 1999;47(6):639-46.

14. Visser M, Pahor M, Taaffe DR, Goodpaster BH, Simonsick EM, Newman AB, Nevitt M, Harris TB. Relationship of interleukin-6 and tumor necrosis factoralpha with muscle mass and muscle strength in elderly men and women: the Health ABC Study. J Gerontol A Biol Sci Med Sci. 2002:57(5):M326-32.

15. Barbieri M, Ferrucci L, Ragno E, Corsi A, Bandinelli S, Bonafe M, Olivieri F, Giovagnetti S, Franceschi C, Guralnik JM, Paolisso G. Chronic inflammation and the effect of IGF-I on muscle strength and power in older persons. Am J Physiol Endocrinol Metab. 2003;284(3):E481-7.

16. Cesari M, Penninx BW, Pahor M, Lauretani F, Corsi AM, Rhys Williams G, Guralnik JM, Ferrucci L. Inflammatory markers and physical performance in older persons: the InCHIANTI study. J Gerontol A Biol Sci Med Sci. 2004; 59(3):242-8.

17. Bautmans I, Njemini R, Lambert M, Demanet C, Mets T. Circulating acute phase mediators and skeletal muscle performance in hospitalized geriatric patients. J Gerontol A Biol Sci Med Sci. 2005;60(3):361-7.

18. Toth MJ, Ades PA, Tischler MD, Tracy RP, LeWinter MM. Immune activation is associated with reduced in chronic heart failure. Int J Cardiol. 2006;109(2):179-87.

19. Yende S, Waterer GW, Tolley EA, Newman AB, Bauer DC, Taaffe DR, Jensen R, Crapo R, Rubin S, Nevitt M, Simonsick EM, Satterfield S, Harris T, Kritchevsky SB. Inflammatory markers are associated with ventilatory limitation and muscle dysfunction in obstructive lung disease in well functioning elderly subjects. Thorax. 2006;61(1):10-6.

20. Boxer RS, Dauser DA, Walsh SJ, Hager WD, Kenny AM. The association between vitamin $D$ and inflammation with the 6-minute walk and frailty in patients with heart failure. J Am Geriatr Soc. 2008;56(3):454-61.

21. Oliveira DM, Narciso FM, Santos ML, Pereira DS, Coelho FM, Dias JM, Pereira LS. Muscle strength but not functional capacity is associated with plasma interleukin-6 levels of community-dwelling elderly women. Braz J Med Biol Res. 2008:41(12):1148-53.

22. Brinkley TE, Leng X, Miller ME, Kitzman DW, Pahor M, Berry MJ, Marsh AP, Kritchevsky SB, Nicklas BJ. Chronic inflammation is associated with low physical function in older adults across multiple comorbidities. J Gerontol A Biol Sci Med Sci. 2009:64(4):455-61.

23. Pereira LS, Narciso FM, Oliveira DM, Coelho FM, Souza Dda G, Dias RC Correlation between manual muscle strength and interleukin-6 (IL-6) plasma levels in elderly community-dwelling women. Arch Gerontol Geriatr. 2009; 48(3):313-6.

24. Tiainen $K$, Hurme $M$, Hervonen A, Luukkaala T, Jylha M. Inflammatory markers and physical performance among nonagenarians. J Gerontol A Biol Sci Med Sci. 2010;65(6):658-63.
25. Bautmans I, Onyema O, Van Puyvelde K, Pleck S, Mets T. Grip work estimation during sustained maximal contraction: validity and relationship with dependency and inflammation in elderly persons. J Nutr Health Aging. 2011;15(8):731-6.

26. Aguirre LE, Jan IZ, Fowler K, Waters DL, Villareal DT, Armamento-Villareal R. Testosterone and adipokines are determinants of physical performance, strength, and aerobic fitness in frail, obese, older adults. Int J Endocrinol. 2014;2014:507395.

27. Patel HP, Al-Shanti N, Davies LC, Barton SJ, Grounds MD, Tellam RL, Stewart CE, Cooper C, Sayer AA. Lean mass, muscle strength and gene expression in community dwelling older men: findings from the Hertfordshire sarcopenia study (HSS). Calcif Tissue Int. 2014;95(4):308-16.

28. Volaklis KA, Halle M, Koenig W, Oberhoffer R, Grill E, Peters A, Strasser B, Heier M, Emeny R, Schulz H, Ladwig KH, Meisinger C, Thorand B. Association between muscular strength and inflammatory markers among elderly persons with cardiac disease: results from the KORA-age study. Clin Res Cardiol. 2015:104(11):982-9.

29. Schaap LA, Pluijm SM, Deeg DJ, Harris TB, Kritchevsky SB, Newman AB, Colbert LH, Pahor M, Rubin SM, Tylavsky FA, Visser M. Higher inflammatory marker levels in older persons: associations with 5-year change in muscle mass and muscle strength. J Gerontol A Biol Sci Med Sci. 2009;64(11):1183-9.

30. Sergi G, Sarti S, Mosele M, Ruggiero E, Imoscopi A, Miotto F, Bolzetta F, Inelmen EM, Manzato E, Coin A. Changes in healthy elderly women's physical performance: a 3-year follow-up. Exp Gerontol. 2011;46(11):929-33.

31. Felicio DC, Pereira DS, Assumpcao AM, Jesus-Moraleida FR, Queiroz BZ, Silva JP, Rosa NM, Dias JM, Pereira LS. Inflammatory mediators, muscle and functional performance of community-dwelling elderly women. Arch Gerontol Geriatr. 2014;59(3):549-53.

32. Soysal P, Stubbs B, Lucato P, Luchini C, Solmi M, Peluso R, Sergi G, Isik AT, Manzato E, Maggi S, Maggio M, Prina AM, Cosco TD, Wu YT, Veronese N. Inflammation and frailty in the elderly: a systematic review and metaanalysis. Ageing Res Rev. 2016;31:1-8.

33. Bano G, Trevisan C, Carraro S, Solmi M, Luchini C, Stubbs B, Manzato E, Sergi G, Veronese N. Inflammation and sarcopenia: a systematic review and metaanalysis. Maturitas. 2017:96:10-5.

34. Ferrucci L, Penninx BW, Volpato S, Harris TB, Bandeen-Roche K, Balfour J, Leveille SG, Fried LP, Md JM. Change in muscle strength explains accelerated decline of physical function in older women with high interleukin-6 serum levels. J Am Geriatr Soc. 2002;50(12):1947-54.

35. Moher D, Liberati A, Tetzlaff J, Altman DG, Group P. Preferred reporting items for systematic reviews and meta-analyses: the PRISMA statement. PLoS One. 2009;6(7):e1000097.

36. von Elm E, Altman DG, Egger M, Pocock SJ, Gotzsche PC, Vandenbroucke JP. The strengthening the reporting of observational studies in epidemiology (STROBE) statement: guildelines for reporting observational studies. J Clin Epidemiol. 2008;61:344-9.

37. Borenstein M, Hedges LV, Higgins JPT, Rothstein HR. Effect sizes based on correlations. In: Borenstein M, Hedges LV, Higgins JPT, Rothstein HR, editors. Introduction to meta-analysis. Chichester: Wiley; 2009. p. 41-3.

38. Wan X, Wang W, Liu J, Tong T. Estimating the sample mean and standard deviation from the sample size, median, range and/or interquartile range. BMC Med Res Methodol. 2014;14:35.

39. Bautmans I, Njemini R, Vasseur S, Chabert H, Moens L, Demanet C, Mets T. Biochemical changes in response to intensive resistance exercise training in the elderly. Gerontology. 2005;51(4):253-65.

40. Bautmans I, Gorus E, Njemini R, Mets T. Handgrip performance in relation to self-perceived fatigue, physical functioning and circulating IL-6 in elderly persons without inflammation. BMC Geriatr. 2007:7:5.

41. linuma T, Arai Y, Fukumoto M, Takayama M, Abe Y, Asakura K, Nishiwaki Y, Takebayashi T, Iwase T, Komiyama K, Gionhaku N, Hirose N. Maximum occlusal force and physical performance in the oldest old: the Tokyo oldest old survey on total health. J Am Geriatr Soc. 2012;60(1):68-76.

42. Marques EA, Mota J, Viana JL, Tuna D, Fiqueiredo P, Guimaraes JT, Carvalho J. Response of bone mineral density, inflammatory cytokines, and biochemical bone markers to a 32-week combined loading exercise programme in older men and women. Arch Gerontol Geriatr. 2013;57(2):226-33

43. Ogawa K, Kim HK, Shimizu T, Abe S, Shiga Y, Calderwood SK. Plasma heat shock protein 72 as a biomarker of sarcopenia in elderly people. Cell Stress Chaperones. 2012;17(3):349-59. 
44. Payette $H$, Roubenoff $R$, Jacques PF, Dinarello CA, Wilson PW, Abad LW, Harris T. Insulin-like growth factor-1 and interleukin 6 predict sarcopenia in very old community-living men and women: the Framingham Heart Study. J Am Geriatr Soc. 2003;51(9):1237-43.

45. Stenholm S, Maggio M, Lauretani F, Bandinelli S, Ceda GP, Di lorio A, Giallauria F, Guralnik JM, Ferrucci L. Anabolic and catabolic biomarkers as predictors of muscle strength decline: the InCHIANTI study. Rejuvenation Res. 2010;13(1):3-11.

46. Aleman H, Esparza J, Ramirez FA, Astiazaran H, Payette H. Longitudinal evidence on the association between interleukin- 6 and C-reactive protein with the loss of total appendicular skeletal muscle in free-living older men and women. Age Ageing. 2011;40(4):469-75.

47. Yudkin JS, Kumari M, Humphries SE, Mohamed-Ali V. Inflammation, obesity, stress and coronary heart disease: is interleukin-6 the link? Atherosclerosis. 2000;148(2):209-14.

48. Goodman MN. Interleukin-6 induces skeletal muscle protein breakdown in rats. Proc Soc Exp Biol Med. 1994;205(2):182-5.

49. Haddad F, Zaldivar F, Cooper DM, Adams GR. IL-6-induced skeletal muscle atrophy. J Appl Physiol. 2005;98(3):911-7.

50. Williams A, Wang JJ, Wang L, Sun X, Fischer JE, Hasselgren PO. Sepsis in mice stimulates muscle proteolysis in the absence of IL-6. Am J Phys. 1998; 275(6 Pt 2):R1983-91.

51. Espat NJ, Auffenberg T, Rosenberg JJ, Rogy M, Martin D, Fang CH, Hasselgren PO, Copeland EM, Moldawer LL. Ciliary neurotrophic factor is catabolic and shares with IL-6 the capacity to induce an acute phase response. Am J Phys. 1996:271(1 Pt 2):R185-90.

52. Leng SX, Cappola AR, Andersen RE, Blackman MR, Koenig K, Blair M, Walston JD. Serum levels of insulin-like growth factor-I (IGF-I) and dehydroepiandrosterone sulfate (DHEA-S), and their relationships with serum interleukin-6, in the geriatric syndrome of frailty. Aging Clin Exp Res. 2004;16(2):153-7.

53. Berghella AM, Contasta I, Marulli G, D'Innocenzo C, Garofalo F, Gizzi F, Friscioni M, Barone M, Del Beato T, Secinaro E, Pellegrini P. Ageing gender-specific "Biomarkers of Homeostasis", to protect ourselves against the diseases of the old age. Immun Ageing. 2014;11(1):3

Ready to submit your research? Choose BMC and benefit from:

- fast, convenient online submission

- thorough peer review by experienced researchers in your field

- rapid publication on acceptance

- support for research data, including large and complex data types

- gold Open Access which fosters wider collaboration and increased citations

- maximum visibility for your research: over $100 \mathrm{M}$ website views per year

At BMC, research is always in progress.

Learn more biomedcentral.com/submissions 